\title{
The Correlation Between 1p/19q Codeletion, IDH1 Mutation, p53 Overexpression and Their Prognostic Roles in 41 Turkish Anaplastic Oligodendroglioma Patients
}

\author{
Payam HACISALIHOGLU', Zafer KUCUKODACl², Gokcen GUNDOGDU³, Bilge BILGIC ${ }^{3}$ \\ ${ }^{1}$ Yeni Yuzyil University, Medical Faculty, Gaziosmanpasa Hospital, Department of Pathology, Istanbul, Turkey \\ ${ }^{2}$ Haydarpasa Sultan Abdulhamit Education and Research Hospital, Department of Pathology, Istanbul, Turkey \\ ${ }^{3}$ Istanbul University, Istanbul Medical Faculty, Department of Pathology, Istanbul, Turkey
}

\section{ABSTRACT}

AIM: To observe the correlation between $1 \mathrm{p} / 19 \mathrm{q}$ codeletion, isocytrate dehydrogenase-1 (IDH1) mutation and p53 protein overexpression and their prognostic value in Turkish anaplastic oligodendroglioma patients who were treated with adjuvant radiotherapy and temozolomide chemotherapy.

MATERIAL and METHODS: We retrospectively evaluated 41 patients who were diagnosed as anaplastic oligodendroglioma. Thirty-five patients received standard radiotherapy. Twenty-six patients received standard temozolomide chemoterapy concurrent to radiotherapy.

RESULTS: Chromosome 1p/19q codeletion was observed in 19 of 41 patients (46\%) via Fluorescent In Situ Hybridisation (FISH) technique. Twenty-six patients (63\%) showed positive immunoreaction with anti-IDH1 antibody. Six patients (15\%) showed positive immunoreaction with anti-p53 antibody. A statistically significant correlation was determined between chromosome $1 p / 19 q$ codeletion and IDH1 mutation $(p<0.0001)$. The patients who had tumors with chromosome $1 p / 19 q$ codeletion and p53 overexpression were mutually exclusive. The mean estimated Progression Free Survival (PFS) of the patients who had tumors with chromosome $1 \mathrm{p} / 19 \mathrm{q}$ codeletion and/or IDH1 mutation was determined to be significantly longer than that of the patients without these genetic changes, regardless of the treatment modality $(p=0.006, p=0.004)$. PFS of the patients who received adjuvant chemotherapy and whose tumors had chromosome $1 \mathrm{p} / 19 \mathrm{q}$ codeletion or IDH1 mutation was significantly longer than that of the patients without these genetic changes $(p=0.001, p<0.0001)$.

CONCLUSION: Chromosome 1p/19q codeletion and/or IDH1 mutation are favorable prognostic factors in anaplastic oligodendroglioma patients, in terms of PFS.

KEYWORDS: Anaplastic oligodendroglioma, 1p/19q codeletion, IDH1 mutation, Temozolomide, Prognosis

\section{INTRODUCTION}

ligodendroglioma is a rare tumor, accounting for about $2.5 \%$ of all primary brain tumors, and $5-6 \%$ of all gliomas (27). Anaplastic oligodendroglioma with chromosome $1 \mathrm{p} / 19 \mathrm{q}$ codeletion is a chemosensitive tumor with better prognosis than their counterparts without deletion. Molecular cytogenetic trials have determined that the codeletion on chromosome $1 \mathrm{p} / 19 \mathrm{q}$ is an early genetic change which plays a significant role in the pathogenesis of oligodendroglioma, and is present more often in oligodendroglioma than any other primary brain tumor $(2,5,8,9,11,14,16,17,19,21,28$, $32,33,35,37,41)$. Numerous clinical trials which have been performed since 1998 have proven the presence of the $1 p / 19 q$ codeletion to be a favorable prognostic and predictive factor in 
anaplastic oligodendroglioma patients who received adjuvant chemotherapy, in addition to surgery and radiotherapy $(5,8-$ $10,14,25,35,41)$.

Isocytrate dehydrogenase-1 (IDH1), which is localised on chromosome 2q33.3, is a gene which encodes cytosolic nicotinamide adenine dinucleotide phosphate (NADP)(+) dependent isocytrate dehydrogenase in humans. It is anenzyme in the citric acid cycle, which catalyses the transformation of cytrate to a-ketoglutarate $(10,29)$. IDH1 is the main resource of NADPH, necessary for the regeneration of reducted cytosolic gluthation, which is the main cellular antioxidant (34). In previous studies, IDH1 mutations specific to gliomas have always been found to effect the arginin aminoacid on codon 132, which encodes the isocytrate binding region (31). As a result of a mutation on this gene, IDH1 enzyme activity is inactivated and an oncometabolite called 2-hydroxyglutarate accumulates (1). Excessive 2-hydroxyglutarate accumulation plays a role in glioma pathogenesis and progression (7). Recent cytogenetic and immunohistochemical studies have shown that the IDH1 mutation is present in significantly higher rates in oligodendrogliomas exhibiting the $1 p / 19 q$ codeletion and is a favorable prognostic marker in terms of progression free survival (PFS) and overall survival (13,24,26,36,39).

The p53 gene is localised on chromosome 17p13.1. This gene encodes a tumor supressor protein called p53 (42). The p53 gene mutation plays an important role in gliogenesis and malignant transformation of human gliomas (6). Chromosome $17 p$ loss and p53 mutation are rarer in oligodendroglial tumors, compared with astrocytic tumors $(19,33,42)$. Studies have shown a negative correlation between chromosome $1 p / 19 q$ codeletion and p53 protein expression in oligodendroglial tumors. Chromosome 1p/19q codeletion and p53 mutation have been found mutually exclusive in some clinical trials $(15,20,33)$. The absence of chromosome $1 p / 19 q$ codeletion and presence of p53 overexpression have been stated to be negative prognostic and predictive factors in oligodendroglial tumors (18).

There is a limited number of studies which have observed chromosome $1 \mathrm{p} / 19 \mathrm{q}$ codeletion, IDH1 mutation and p53 protein overexpression at the same time, in anaplastic oligodendroglioma patients who received adjuvant temozolomide chemotherapy $(26,40,44)$.

The aim of our study was to analyze the correlation between $1 \mathrm{p} / 19 \mathrm{q}$ codeletion, IDH1 mutation and p53 protein overexpression and to determine their prognostic and predictive roles in anaplastic oligodendroglioma patients who received adjuvant temozolomide chemotherapy, in addition to surgery and radiotherapy.

\section{- MATERIAL and METHODS}

\section{Clinical Material}

In our study, we retrospectively evaluated 41 patients who were diagnosed as anaplastic oligodendroglioma in Istanbul University, Istanbul Medical Faculty, Pathology Department, between 2004 and 2011. Twelve of the cases were determined to be patients with recurrent tumors. We accessed the clinical data, including patient age at diagnosis, sex, operation status, treatment modalities of 36 of 41 patients which have been included in our study. Prognostic statistical analysis was performed on the data obtained from those patients. PFS, defined as the period from primary diagnosis to first progression of the disease, was collected from the patient files. The study was approved by the Ethics Committee of Istanbul University, Istanbul Medical Faculty Hospital.

\section{Treatment}

Standard treatment consisted of surgery and postoperative radiotherapy, with or without adjuvant temozolomide chemotherapy. Maximal tumor bulk resection while preserving the key eloquent cortex was the principle goal during surgery. Preoperative functional magnetic resonance image (MRI) and intraoperative awake brain mapping were used when necessary. Extent of resection was assessed on the postoperative enhanced MRI within 24 hours and graded as total or subtotal resection. Thirty-five of the patients received 54-60 Gray adjuvant radiotherapy for 35 days. One patient did not receive radiotherapy due to the tumor localization. Twenty-six patients received $75 \mathrm{mg} / \mathrm{m}^{2} /$ day adjuvant temozolomide chemotherapy concurrent to radiotherapy. These patients received $200 \mathrm{mg} / \mathrm{m}^{2}$ temozolomide for 5 days post radiotherapy and continued receiving $200 \mathrm{mg} / \mathrm{m}^{2}$ temozolomide once a month for 6 months. Ten patients did not receive chemotherapy.

\section{Assessment of chromosome 1p/19q deletion}

Chromosome $1 p / 19 q$ statuses of the patients was assessed on paraffin-embedded blocks of the tumor samples of the patients with the Fluorescent In Situ Hybridisation (FISH) technique. In each case, hematoxylin-eosin slides were reevaluated, and the tumor areas with the most prominent anaplastic features, with no necrosis or hemorrhage were selected. Two $4 \mu \mathrm{m}$ thick sections were obtained from the paraffin embedded tumor blocks. In the FISH technique, for the assessment of chromosome 1p status, a dual colored FISH probe which contains a mixture of $\mathrm{a} \sim 435 \mathrm{~kb}$ SpectrumOrangelabeled 1p36 probe and a 618 kb SpectrumGreen-labeled 1 q25 probe premixed in hybridization buffer (The Vysis LSI 1 p36 SpectrumOrange/1q25 SpectrumGreen Probe, Vysis Abbott Laboratories, Abbot Park, IL, USA); for the assessment of chromosome 19q status, a dual colored FISH probe which contains a mixture of a 380 kb SpectrumOrange-labeled $19 q 13$ probe and a 502 kb SpectrumGreen-labeled 19p13 probe premixed in hybridization buffer (The Vysis LSI 19q13 SpectrumOrange/19p13 SpectrumGreen Probe, Vysis Abbott Laboratories, Abbott Park, IL, USA) were used. For the interpretation of chromosome $1 p$ and $19 q$ deletion, a FISH protocol including deparaffinization, pre-hybridization and hybridization steps was used.

To determine the chromosome $1 p / 19 q$ status, the orange subtelomeric (determining) and green paracentromeric (reference) signals in 200 collateral cells were counted and photomicrographically documented by an experienced molecular pathologist. The ratio of orange/green signals less than 0.70 was considered to be a deletion. In cases which were difficult 
to assess, the number of cells whose signals were counted were increased to 300 .

\section{Assessment of IDH1 mutation}

IDH1 mutation was assessed immunohistochemically by using mutant IDH1 protein specific anti-IDH1 antibody (anti-human IDH1 $\mathrm{R} 132 \mathrm{H}$ astrocytoma, oligodendroglioma tumor cell marker mouse monoclonal antibody clone H09, Dianova GmbH Warbugstrasse 45 D-20354 Hamburg, Germany). Positive control tissues were included in all experiments to ensure the quality of staining. Nuclear and cytoplasmic stainings in tumor cells was regarded as positive immunostaining.

\section{Assessment of p53 protein overexpression}

p53 protein overexpression was assessed immunohistochemically by using p53 Ab-8, Mouse monoclonal antibody clone DO-7+BP53-12. Thermo Fisher Scientific Inc. 81 Wyman Street Waltham, MA, 02454, USA). Positive control tissues were included in all experiments to ensure the quality of staining. A nuclear staining which is observed more than $10 \%$ of the tumor cells was regarded as positive immunos- taining. The immunohistochemical analyses were interpreted by two experienced pathologists (Figure 1A-D).

\section{Biostatistical analysis}

The biostatistical analysis of our study was implemented using the Statistical Package for Social Sciences 21.0 program. For recurrence and survival analysis, Kaplan Meier survival analysis, for all other categorical variables chi-square test, for the assessment of the factors which affect time to progression, cox regression analysis was used. $p$ value $\leq 0.05$ was granted to be statistically significant.

\section{- RESULTS}

We assessed the tumor samples of 41 patients who were diagnosed as anaplastic oligodendroglioma between 20042011 in our pathology department. Twelve patients' tumors have been diagnosed as anaplastic oligodendroglioma before, in other centers. We assessed their recurrent tumors. The ages of the patients at time of diagnosis ranged between 12 and 63 years. The main age of the patients at the time of diagnosis

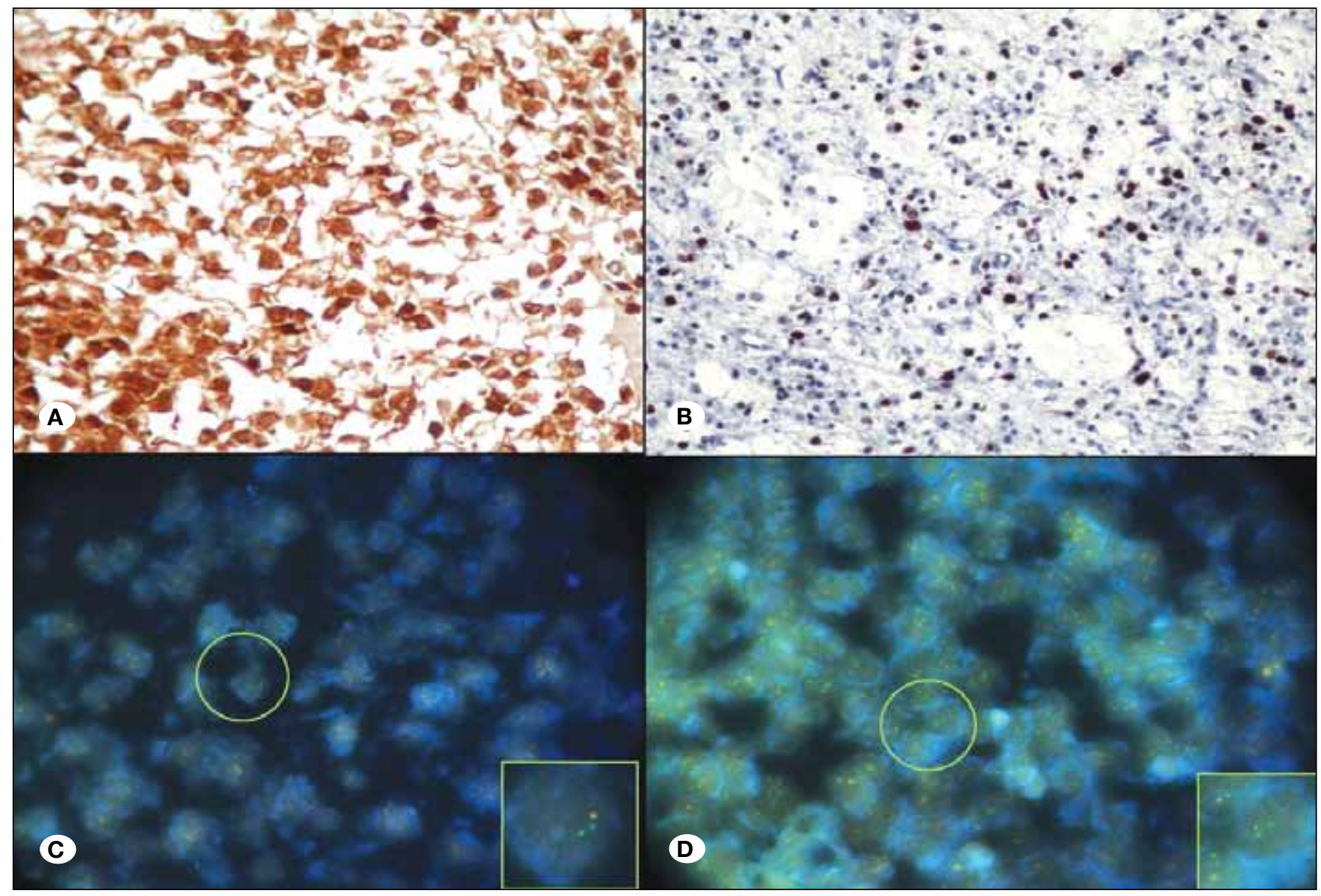

Figure 1: A) Anaplastic oligodendroglioma with positive immunoreaction with anti-IDH1 antibody, (anti-IDH1 antibody, X400). B) Anaplastic oligodendroglioma with positive immunoreaction with anti-p53 antibody, (anti-p53 antibody, X400). C) Detection of chromosome 1p deletion by FISH in anaplastic oligodendroglioma, (FISH, chromosome 1p probe, X1000). D) Detection of chromosome 19q deletion by FISH in anaplastic oligodendroglioma, (FISH, chromosome 19q probe, X1000). 
was 41.7 years. Twenty one of 41 patients were female. Male/ female ratio was 0.95 . Seventeen of the patients' tumors were located at parietal region. Fifteen patients had frontally, 8 patients had temporally, and 1 patient had occipitally located tumors. Twenty-nine patients $(71 \%)$ underwent total tumor resection. The mean clinical follow-up of the patients was 70.4 months. We observed recurrent anaplastic oligodendroglioma in 28 patients. The mean PFS of the patients was 59.2 months (Table I). Nine patients died from anaplastic oligodendroglioma during the follow-up time.

\section{Chromosome 1p/19q codeletion}

We observed chromosome $1 p$ deletion in 23 of 41 patients (56\%). Nineteen patients (46\%) had chromosome 19q deletion. We could not get any signals on chromosome $19 q$ on tumor sample of one patient in spite of two times repetation. Nineteen patients $(46 \%)$ had chromosome $1 p / 19 q$ codeletion. Three patients $(7 \%)$ had chromosome $1 p$ deletion, but did not have chromosome $19 q$ deletion.

\section{IDH1 mutation}

Twenty-six patients (63\%) showed positive immunoreaction with mutant protein spesific anti-IDH1 antibody.

\section{p53 protein overexpression}

Six patients (15\%) showed positive immunoreaction with anti-p53 antibody.

\section{Statistical Analysis}

We accessed the clinical data of 36 of 41 patients. The prognostic statistical analysis were performed on the data obtained from those patients.

Correlation between chromosome $1 p / 19 q$ codeletion, IDH1 mutation and p53 protein overexpression

Ninety percent of patients (17 of 19) who had tumors with chromosome $1 p / 19 q$ codeletion showed positive immunoreaction with anti-IDH1 antibody $(p<0.0001$, Chisquare, log rank). Two of 3 patients who had tumors with chromosome $1 p$, but not $19 q$ deletion showed positive immunoreaction with anti-IDH1 antibody. In our study, the patients who had tumors with chromosome $1 \mathrm{p} / 19 \mathrm{q}$ codeletion and p53 overexpression were mutually exclusive $(p=0.01$, Chi-square, log rank). Twelve percent of patients (3 of 26) with IDH1 mutation showed p53 protein expression, whereas $20 \%$ of patients ( 3 of 15 ) without IDH1 mutation showed p53 protein expression.

\section{Factors associated with Progression Free Survival (PFS)}

The mean estimated PFS of the patients who had tumors with chromosome $1 p / 19 q$ codeletion was $73.4 \pm 13$ months, ( $p=0.004$, Kaplan-Meier, log rank). The mean estimated PFS of the patients who had tumors with IDH1 mutation was $73.2 \pm 12.5$ months, $(p=0.004$, Kaplan-Meier, log rank). The mean estimated PFS of the patients who had tumors with $1 p / 19 q$ codeletion together with IDH1 mutation was $75.9 \pm 13.6$ months, ( $p=0.006$, Kaplan-Meier, log rank)(Figure 2).
The mean estimated PFS of the patients who received adjuvant temozolomide chemotherapy in addition to radiotherapy, and whose tumors had chromosome $1 p / 19 q$ codeletion was $64.3 \pm 15$ months, while that of the patients without $1 p / 19 q$ codeletion was $18.3 \pm 5.2$ months $(p=0.001$,

Table I: General Characteristics of the Patients in Our Study

Variable

Anaplastic oligodendroglioma patients $(n=41)$

\begin{tabular}{lc}
\hline Mean age at diagnosis (years) & 41.7 \\
\hline Sex & 21 \\
\hline Female & 20 \\
\hline Male & 29 \\
\hline Extent of tumor resection & 9 \\
\hline Total & \\
\hline Subtotal & 35 \\
\hline Radiotherapy & 1 \\
\hline No
\end{tabular}

Temozolomide chemotherapy

\begin{tabular}{cc}
\hline Yes & 26 \\
\hline No & 10 \\
\hline Chromosome 1p deletion \\
\hline Yes & 23 \\
\hline No & 18 \\
\hline
\end{tabular}

Chromosome 19q deletion

\begin{tabular}{cc}
\hline Yes & 19 \\
\hline No & 21 \\
\hline
\end{tabular}

Chromosome 1p/19q codeletion

\begin{tabular}{cc}
\hline Yes & 19 \\
\hline No & 18 \\
\hline IDH1 mutation & \\
\hline Yes & 26 \\
\hline No & 15 \\
\hline
\end{tabular}

p53 protein overexpression

\begin{tabular}{cl}
\hline Yes & 6 \\
\hline No & 35 \\
\hline Mean follow up time (months) & 70.4 \\
\hline Mean PFS (months) & 59.2 \\
\hline
\end{tabular}


Kaplan-Meier, log rank)(Figure 3A). The mean estimated PFS of the patients whose tumors had IDH1 mutation and who received temozolomide chemotherapy was $68.9 \pm 14.5$ months while that of the patients without IDH1 mutation was $12.2 \pm 2.5$ months $(p<0.0001$, Kaplan-Meier, log rank)(Figure 3B). In our study, the number of the patients whose tumors showed p53 expression was not sufficient enough to perform the statistical survival analysis.

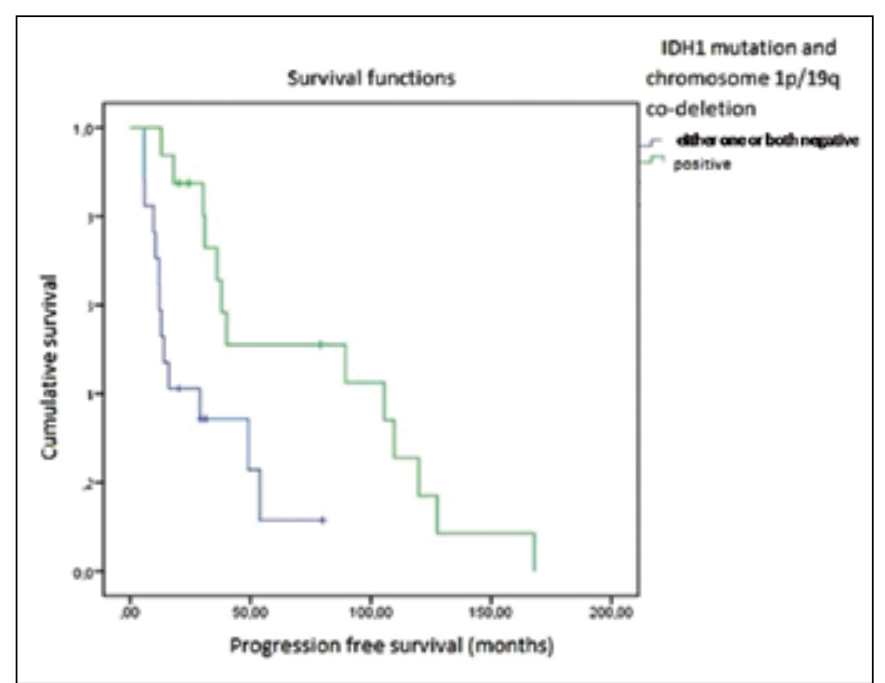

Figure 2: The mean estimated PFS of the patients who had tumors with $1 p / 19 q$ codeletion together with IDH1 mutation was 75.9 months. This period was statistically significant longer than that of the patients with chromosome $1 p / 19 q$ codeletion without IDH1 mutation, IDH1 mutation without chromosome $1 p / 19 q$ codeletion, and of the patients with neither chromosome $1 p / 19 q$ codeletion nor IDH1 mutation (29 months), ( $p=0.006$, KaplanMeier, log rank).

\section{DISCUSSION}

Previously, the gold standard method in diagnosis and grading of gliomas was based on the histopathological features of the tumors (hypercellularity, mitosis, necrosis and vascular endothelial proliferation). In order to provide a better prediction and therapy management, a need for a more advanced and objective classification has emerged and the number of studies revealing the genetic changes in gliomas have been rapidly increasing (22).

Anaplastic oligodendroglioma is a chemosensitive tumor. Chromosome $1 \mathrm{p} / 19 \mathrm{q}$ codeletion is a predictive factor in response to chemotherapy and is a positive prognostic factor by means of survival. This fact was proven first in 1998, by Cairncross et al., and was supported by numerous studies which have taken place in the following years $(4,14,25,30)$.

European Organisation for Research and Treatment of Cancer (EORTC) and Radiation Therapy Oncology Group (RTOG) studies, which have been conducted for over 40 years on glioma patients, are randomised, multi-centered phase III studies, including patients with long term follow-up. In a report of Kouwenhoven et al. on EORTC 26951 study, it is concluded that chromosome $1 p / 19 q$ codeletion is the most powerful molecular prognostic marker in anaplastic oligodendroglioma patients (23). In RTOG 9402 study, the patients who had tumors with $1 p / 19 q$ codeletion and received Procarbazine, Lomustine, and Vincristine (PCV) chemotherapy in addition to radiotherapy had significantly longer overall survival than the patients who had tumors without $1 p / 19 q$ codeletion (3). In a study of van den Bent et al., which represents the long term follow-up of EORTC 26951, the anaplastic oligodendroglioma patients who had tumors with chromosome $1 \mathrm{p} / 19 \mathrm{q}$ codeletion and treated with six cycles adjuvant PCV chemotherapy, received statistically significant more benefit from the chemotherapy regimen (38).

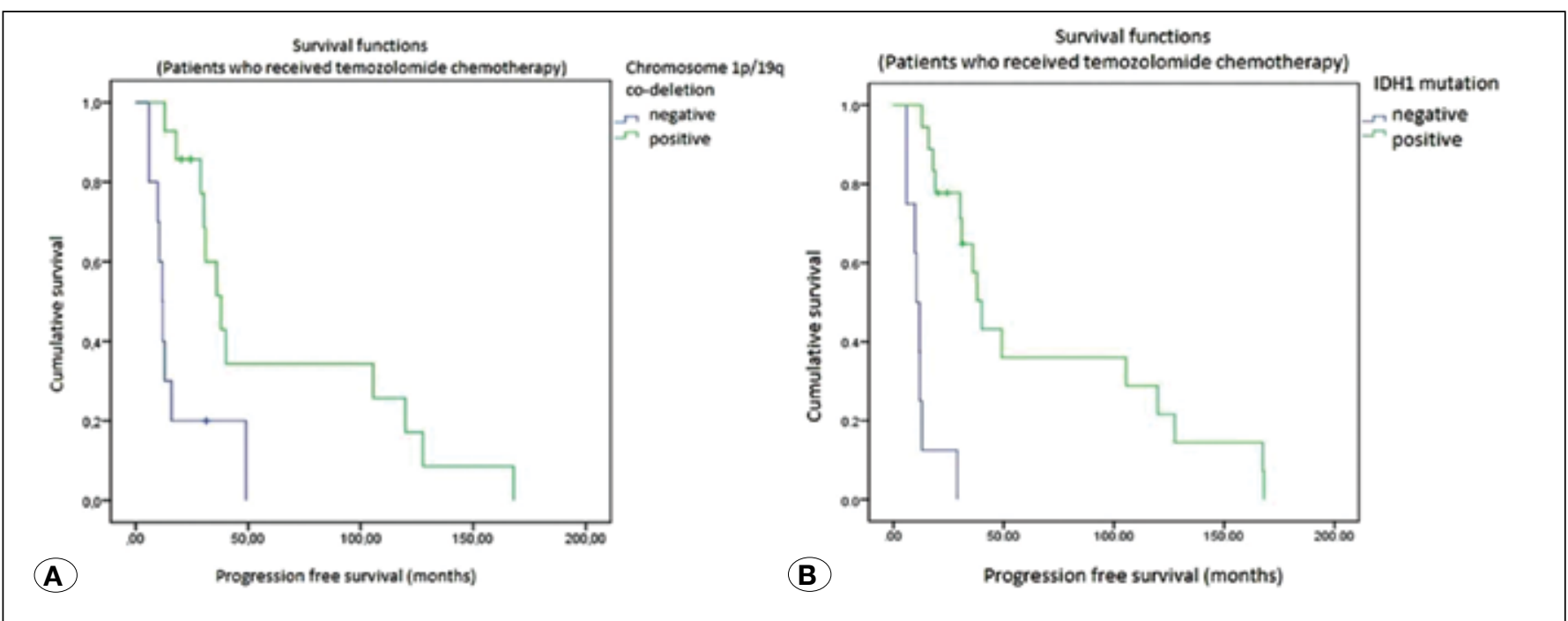

Figure 3: A) The mean estimated PFS of the patients with and without 1p/19q codeletion, who received adjuvant temozolomide chemotherapy in addition to radiotherapy was 64.3 vs 18.3 months respectively, $(p=0.001$, Kaplan-Meier, log rank). B) The mean estimated PFS of the patients with and without IDH1 mutation, who received adjuvant temozolomide chemotherapy in addition to radiotherapy was 68.9 vs 12.2 months respectively, ( $p=0.001$, Kaplan-Meier, log rank). 
Gorlia et al., in a prognostic analysis of the EORTC 26951 study, stated that both chromosome $1 \mathrm{p} / 19 \mathrm{q}$ codeletion and IDH1 mutation are favorable prognostic factors in terms of overall survival (OS) and PFS in anaplastic oligodendroglioma patients. They concluded that the detection of chromosome $1 \mathrm{p} / 19 \mathrm{q}$ codeletion together with IDH1 mutation should be used in routine practice to determine the prognosis in anaplastic oligodendroglioma patients (12).

Other recently performed cytogenetic and immunohistochemical studies have also determined that the IDH1 mutation which was shown to be in correlation with the $1 p / 19 q$ codeletion is also a favorable prognostic marker for anaplastic oligodendroglioma patients who received adjuvant chemotherapy $(24,26,36,39)$.

In our study, we aimed to show the prognostic role of these genetic changes in Turkish anaplastic oligodendroglioma patients who received adjuvant temozolomide chemotherapy.

\section{The role of genetic changes on prognosis}

As a result of our study, parallel with the previous studies, we found a correlation between the number of the cases with $1 p / 19 q$ codeletion and IDH1 mutation $(p<0.0001)$. As a result of our study, chromosome $1 \mathrm{p} / 19 \mathrm{q}$ codeletion and/or IDH1 mutation are determined to be statistically significant favorable prognostic factors in anaplastic oligodendroglioma patients, in terms of PFS ( $p=0.004, p=0.006)$.

\section{The role of the genetic changes in response to temozolomide chemotherapy}

In our study, the mean estimated PFS of the patients who received adjuvant temozolomide chemotherapy in addition to radiotherapy, and whose tumors had chromosome $1 p / 19 q$ codeletion was significantly longer than the patients without $1 p / 19 q$ codeletion $(p=0.004)$. The mean estimated PFS of the patients whose tumors had IDH1 mutation and received adjuvant temozolomide chemotherapy was significantly longer than the patients without IDH1 mutation $(\mathrm{p}<0.0001)$. Although we accessed statistically significant results, due to the retrospective nature of our study, the number of patients was not sufficient enough to determine the predictive role of these genetic changes for the benefit from temozolomide chemotherapy. Like our study, all of the previous studies which have been performed up to date could not determine the predictive role of IDH1 mutation on chemotherapy in anaplastic oligodendroglioma patients $(7,12,39-41,43)$.

\section{CONCLUSION}

Chromosome 1p/19q codeletion and/or IDH1 mutation are determined to be statistically significant favorable prognostic factors in anaplastic oligodendroglioma patients, in terms of PFS. In order to determine the IDH1 mutation's predictive role for the benefit from chemotherapy in anaplastic oligodendroglioma patients, prospective studies with sufficient number of patients are needed to be performed in the future.

\section{REFERENCES}

1. Andronesi OC, Kim GS, Gerstner E, Batchelor T, Tzika AA, Fantin VR, Vander Heiden MG, Sorensen AG: Detection of 2 hydroxyglutarate in IDH-mutated glioma patients by in vivo spectral-editing and 2D correlation magnetic resonance spectroscopy. Sci Transl Med 4: 116, 2012

2. Bigner SH, Matthews MR, Rasheed BK, Wiltshire RN, Friedman HS, Friedman AH, Stenzel TT, Dawes DM, McLendon RE, Bigner DD: Molecular genetic aspects of oligodendrogliomas including analysis by comparative genomic hybridization. Am J Pathol 155:375-386, 1999

3. Cairncross G, Wang M, Shaw E, Jenkins R, Brachman D, Buckner J, Fink K, Souhami L, Laperriere N, Curran W, Mehta M: Phase III trial of chemoradiotherapy for anaplastic oligodendroglioma: Long-term results of RTOG 9402. J Clin Oncol 31: 337-343, 2013

4. Cairncross JG, Ueki K, Zlatescu MC, Lisle DK, Finkelstein DM, Hammond RR, Silver JS, Stark PC, Macdonald DR, Ino Y, Ramsay DA, Louis DN: Specific genetic predictors of chemotherapeutic response and survival in patients with anaplastic oligodendrogliomas. J Natl Cancer Inst 90: 14731479, 1998

5. Chaturbedi A, Yu L, Linskey ME, Zhou Y: Detection of 1p19q deletion by Real-Time comparative Quantitative PCR. Biomark Insights 7: 9-17, 2012

6. Cui W, Kong X, Cao HL, Wang X, Gao JF, Wu RL, Wang XC: Mutations of p53 gene in 41 cases of human brain gliomas. Ai Zheng 27: 8-11, 2008 (In Chinese)

7. Dang L, White DW, Gross S, Bennett BD, Bittinger MA, Driggers EM, Fantin VR, Jang HG, Jin S, Keenan MC, Marks KM, Prins RM, Ward PS, Yen KE, Liau LM, Rabinowitz JD, Cantley LC, Thompson CB, Vander Heiden MG, Su SM: Cancer-associated IDH1 mutations produce 2-hydroxyglutarate. Nature 465: 966, 2010

8. Felsberg J, Erkwoh A, Sabel MC, Kirsch L, Fimmers R, Blaschke B, Schlegel U, Schramm J, Wiestler OD, Reifenberger G: Oligodendroglial tumors: Refinement of candidate regions on chromosome arm $1 p$ and correlation of $1 p / 19 q$ status with survival. Brain Pathol 14: 121-130, 2004

9. Fontaine D, Vandenbos F, Lebrun C, Paquis V, Frenay M: Diagnostic and prognostic values of $1 p$ and $19 q$ deletions in adult gliomas: Critical review of the literature and implications in daily clinical practice. Rev Neurol (Paris) 164: 595-604, 2008

10. French PJ, Swagemakers SM, Nagel JH, Kouwenhoven MC, Brouwer E, van der Spek P: Gene expression profiles associated with treatment response in oligodendrogliomas. Cancer Res 65: 11335-11344, 2005

11. Gelpi E, Ambros IM, Birner P, Luegmayr A, Drlicek M, Fischer I, Kleinert R, Maier H, Huemer M, Gatterbauer B, Anton J, Rössler K, Budka H, Ambros PF, Hainfellner JA: Fluorescent in situ hybridization on isolated tumor cell nuclei: A sensitive method for $1 p$ and $19 q$ deletion analysis in paraffin-embedded oligodendroglial tumor specimens. Mod Pathol 16: 708-715, 2003 
12. Gorlia T, Delattre JY, Brandes AA, Kros JM, Taphoorn MJ, Kouwenhoven MC, Bernsen HJ, Frénay M, Tijssen CC, Lacombe D, van den Bent MJ. Gorlia T, Delattre JY, Brandes AA, Kros JM, Taphoorn MJ, Kouwenhoven MC, Bernsen HJ, Frénay $M$, Tijssen CC, Lacombe $D$, van den Bent MJ: New clinical, pathological and molecular prognostic models and calculators in patients with locally diagnosed anaplastic oligodendroglioma or oligoastrocytoma. A prognostic factor analysis of European Organisation for Research and Treatment of Cancer Brain Tumour Group Study 26951. Eur J Cancer 49: 3477-3485, 2013

13. Ichimura K, Pearson DM, Kocialkowski S, Bäcklund LM, Chan R, Jones DT, Collins VP: IDH1 mutations are present in the majority of common adult gliomas but rare in primary glioblastomas. Neuro Oncol 11: 341-347, 2009

14. Ino Y, Betensky RA, Zlatescu MC, Sasaki H, Macdonald DR, Stemmer-Rachamimov AO, Ramsay DA, Cairncross JG, Louis DN: Molecular subtypes of anaplastic oligodendroglioma: Implications for patient management at diagnosis. Clin Cancer Res 7: 839-845, 2001

15. Ino $Y$, Zlatescu MC, Sasaki $H$, Macdonald DR, Rachamimov AO, Jhung S, Ramsay DA, von Deimling A, Louis DN, Cairncross JG: Long survival and therapeutic responses in patients with histologically disparate high-grade gliomas demonstrating chromosome 1p loss. J Neurosurg 92: 983990, 2000

16. Jansen M, Yip S, Louis DN: Molecular pathology in adult gliomas: Diagnostic, prognostic, and predictive markers. Lancet Neurol 9: 717-726, 2010

17. Jenkins RB, Curran W, Scott CB, Cairncross G: Pilot evaluation of $1 p$ and $19 q$ deletions in anaplastic oligodendrogliomas collected by a national cooperative cancer treatment group. Am J Clin Oncol 24: 506-508, 2001

18. Jeon YK, Park K, Park CK, Paek SH, Jung HW, Park SH: Chromosome $1 p$ and $19 q$ status and p53 and p16 expression patterns as prognostic indicators of oligodendroglial tumors: A clinicopathological study using fluorescence in situ hybridization. Neuropathology 27: 10-20, 2007

19. Jeuken JW, Sprenger SH, Boerman $\mathrm{RH}$, von Deimling $A$, Teepen HL, van Overbeeke JJ, Wesseling P: Subtyping of oligoastrocytic tumours by comparative genomic hybridization. J Pathol 194: 81-87, 2001

20. Jeuken JW, von Deimling A, Wesseling $P$ : Molecular pathogenesis of oligodendroglial tumors. J Neurooncol 70: 161-181, 2004

21. Ji X, Ying L, Yin W, Rong-hu K, Ying $M$, Zhu-rong $Y$ : Chromosome $1 p / 19 q$ status combined with expression of p53 protein improves the diagnostic and prognostic evaluation of oligodendrogliomas. Chin Med J (Engl) 123: 3566-3573, 2010

22. Korshunov A, Meyer J, Capper D, Christians A, Remke M, Witt H, Pfister S, von Deimling A, Hartmann C: Combined molecular analysis of BRAF and IDH1 distinguishes pilocytic astrocytoma from diffuse astrocytoma. Acta Neuropathol 118: 401-405, 2009
23. Kouwenhoven MC, Gorlia T, Kros JM, Ibdaih A, Brandes AA, Bromberg JE, Mokhtari K, van Duinen SG, Teepen JL, Wesseling P, Vandenbos F, Grisold W, Sipos L, Mirimanoff R, Vecht CJ, Allgeier A, Lacombe D, van den Bent MJ: Molecular analysis of anaplastic oligodendroglial tumors in a prospective randomized study: A report from EORTC study 26951. Neuro Oncol 11: 737-746, 2009

24. Labussière $M$, Idbaih $A$, Wang XW, Marie $Y$, Boisselier $B$, Falet C, Paris S, Laffaire J, Carpentier C, Crinière E, Ducray F, El Hallani S, Mokhtari K, Hoang-Xuan K, Delattre JY, Sanson M: All the $1 \mathrm{p} 19 \mathrm{q}$ deleted gliomas are IDH1 mutated. Neurology 74: 1886-1990, 2010

25. Lassman AB, Iwamoto FM, Cloughesy TF, Aldape KD, Rivera AL, Eichler AF, Louis DN, Paleologos NA, Fisher BJ, Ashby LS, Cairncross JG, Roldán GB, Wen PY, Ligon KL, Schiff D, Robins HI, Rocque BG, Chamberlain MC, Mason WP, Weaver SA, Green RM, Kamar FG, Abrey LE, DeAngelis LM, Jhanwar SC, Rosenblum MK, Panageas KS: International retrospective study of over 1000 adults with anaplastic oligodendroglial tumors. Neuro Oncol 13: 649-659, 2011

26. Li S, Yan C, Huang L, Qiu X, Wang Z, Jiang T: Molecular prognostic factors of anaplastic oligodendroglial tumors and its relationship: A single institutional review of 77 patients from China. Neuro Oncol 14: 109-116, 2012

27. Louis DN, Ohgaki H, Wiestler OD, Cavenee WK: Anaplastic oligodendroglioma. In: Louis DN, Ohgaki H, Wiestler OD, Cavenee WK (eds). World Health Organization (WHO) Classification of Tumours of the Central Nervous System. Lyon: IARC, 2007: 54

28. Maintz D, Fiedler K, Koopmann J, Rollbrocker B, Nechev S, Lenartz D, Stangl AP, Louis DN, Schramm J, Wiestler OD, von Deimling A: Molecular genetic evidence for subtypes of oligoastrocytomas. J Neuropathol Exp Neurol 56: 1098-1104, 1997

29. Narahara K, Kimura S, Kikkawa K, Takahashi Y, Wakita Y, Kasai R, Nagai S, Nishibayashi Y, Kimoto H: Probable assignment of soluble isocitrate dehydrogenase (IDH1) to 2q33.3. Hum Genet 71: 37-40, 1985

30. Nutt CL, Noble M, Chambers AF, Cairncross JG: Differential expression of drug resistance genes and chemosensitivity in glial cell lineages correlate with differential response of oligodendrogliomas and astrocytomas to chemotherapy. Cancer Res 60: 4812-4818, 2000

31. Parsons DW, Jones S, Zhang X, Lin JC, Leary RJ, Angenendt P, Mankoo P, Carter H, Siu IM, Gallia GL, Olivi A, McLendon R, Rasheed BA, Keir S, Nikolskaya T, Nikolsky Y, Busam DA, Tekleab H, Diaz LA Jr, Hartigan J, Smith DR, Strausberg RL, Marie SK, Shinjo SM, Yan H, Riggins GJ, Bigner DD, Karchin R, Papadopoulos N, Parmigiani G, Vogelstein B, Velculescu VE, Kinzler KW: An integrated genomic analysis of human glioblastoma multiforme. Science 321: 1807-1812, 2008

32. Reifenberger G, Louis DN: Oligodendroglioma: Toward molecular definitions in diagnostic neuro-oncology. $J$ Neuropathol Exp Neurol 62: 111-126, 2003

33. Reifenberger J, Reifenberger G, Liu L, James CD, Wechsler W, Collins VP: Molecular genetic analysis of oligodendroglial tumors shows preferential allelic deletions on 19q and 1p. Am J Pathol 145: 1175-1190, 1994 
34. Sanson M, Marie Y, Paris S, Idbaih A, Laffaire J, Ducray F, El Hallani S, Boisselier B, Mokhtari K, Hoang-Xuan K, Delattre JY: Isocitrate dehydrogenase 1 codon 132 mutation is an important prognostic biomarker in gliomas. J Clin Oncol 27: 4150-4154, 2009

35. Sonabend AM, Lesniak MS: Oligodendrogliomas: Clinical significance of $1 p$ and $19 q$ chromosomal deletions. Expert Rev Neurother 5: 25-32, 2005

36. Takano S, Kato Y, Yamamoto T, Kaneko MK, Ishikawa E, Tsujimoto Y, Matsuda M, Nakai K, Yanagiya R, Morita S, Tsuboi K, Matsumura A: Immunohistochemical detection of IDH1 mutation, p53, and internexin as prognostic factors of glial tumors. J Neurooncol 108: 361-373, 2012

37. Ueki K, Nishikawa R, Nakazato Y, Hirose T, Hirato J, Funada $\mathrm{N}$, Fujimaki T, Hojo S, Kubo O, Ide T, Usui M, Ochiai C, Ito $\mathrm{S}$, Takahashi H, Mukasa A, Asai A, Kirino T: Correlation of histology and molecular genetic analysis of 1p, 19q,10q, TP53, EGFR, CDK4, and CDKN2A in 91 astrocytic and oligodendroglial tumors. Clin Cancer Res 8:196-201, 2002

38. van den Bent MJ, Brandes AA, Taphoorn MJ, Kros JM, Kouwenhoven MC, Delattre JY, Bernsen HJ, Frenay M, Tijssen CC, GrisoldW, Sipos L, Enting RH, French PJ, Dinjens WN, Vecht CJ, Allgeier A, Lacombe D, Gorlia T, Hoang-Xuan K: Adjuvant procarbazine, lomustine, and vincristine chemotherapy in newly diagnosed anaplasticoligodendroglioma: Long-term follow-up of EORTC brain tumor group study 26951. J Clin Oncol 31: 344-350, 2013

39. van den Bent MJ, Dubbink HJ, Marie Y, Brandes AA, Taphoorn MJ, Wesseling P, Frenay M, Tijssen CC, Lacombe D, Idbaih A, van Marion R, Kros JM, Dinjens WN, Gorlia T, Sanson M: IDH1 and IDH2 mutations are prognostic but not predictive for outcome in anaplastic oligodendroglial tumors: A report of the European Organization for Research and Treatment of Cancer Brain Tumor Group. Clin Cancer Res 16: 1597-1604, 2010
40. Watanabe T, Nobusawa S, Kleihues P, Ohgaki H: IDH1 Mutations are early events in the development of astrocytomas and oligodendrogliomas. Am J Pathol 174: 1149-1153, 2009

41. Woehrer A, Sander P, Haberler C, Kern S, Maier H, Preusser M, Hartmann C, Kros JM, Hainfellner JA: FISH-based detection of $1 p 19 q$ codeletion in oligodendroglial tumors: procedures and protocols for neuropathological practice - a publication under the auspices of the Research Committee of the European Confederation of Neuropathological Societies (Euro-CNS). Clin Neuropathol 30: 47-55, 2011

42. Xiong J, Liu Y, Li C, Zhu JJ, Ye ZR, Mao Y, Wang Y: Loss of heterozygosity of chromosome $1 p / 19 q$ and p53 protein expression in oligodendroglioma. Zhonghua Bing Li Xue Za Zhi 38: 445-450, 2009 (In Chinese)

43. Yan H, Parsons DW, Jin G, McLendon R, Rasheed BA, Yuan W, Kos I, Batinic-Haberle I, Jones S, Riggins GJ, Friedman H, Friedman A, Reardon D, Herndon J, Kinzler KW, Velculescu VE, Vogelstein B, Bigner DD: IDH1 and IDH2 mutations in gliomas. N Engl J Med 360: 765-773, 2009

44. Yip S, Butterfield YS, Morozova O, Chittaranjan S, Blough MD, An J, Birol I, Chesnelong C, Chiu R, Chuah E, Corbett R, Docking R, Firme M, Hirst M, Jackman S, Karsan A, Li H, Louis DN, Maslova A, Moore R, Moradian A, Mungall KL, Perizzolo M, Qian J, Roldan G, Smith EE, Tamura-Wells J, Thiessen N, Varhol R, Weiss S, Wu W, Young S, Zhao Y, Mungall AJ, Jones SJ, Morin GB, Chan JA, Cairncross JG, Marra MA: Concurrent CIC mutations, IDH mutations, and $1 \mathrm{p} / 19 \mathrm{q}$ loss distinguish oligodendrogliomas from other cancers. J Pathol 226: 7-16, 2012 